\title{
Prevalence of depression among school going adolescents in India: a systematic review and meta-analysis of cross-sectional studies
}

\author{
Prashanthi Kamath $^{1 *}$, Sushma Marita Dsouza², Subhransu Mahapatra ${ }^{2}$, Sruthi Jayakumar ${ }^{3}$
}

\author{
${ }^{1}$ Department of Community Medicine, Indian Institute of Public Health, Hyderabad, India \\ ${ }^{2}$ International Institute for Population Sciences, Mumbai, Maharashtra, India \\ ${ }^{3}$ Chest Research Foundation, Pune, India
}

Received: 10 November 2020

Revised: 31 December 2020

Accepted: 05 January 2021

\author{
*Correspondence: \\ Prashanthi Kamath, \\ E-mail: kamat.prashanti@gmail.com
}

Copyright: () the author(s), publisher and licensee Medip Academy. This is an open-access article distributed under the terms of the Creative Commons Attribution Non-Commercial License, which permits unrestricted non-commercial use, distribution, and reproduction in any medium, provided the original work is properly cited.

\begin{abstract}
The objective of this systematic review was to estimate the pooled prevalence of depression among schoolgoing adolescents in India by using Beck's Depression Inventory (BDI 1 or BDI 2). A systematic literature search was conducted in PubMed, Ovid MEDLINE, Ovid EMBASE, CINAHL, Cochrane Library, PsycINFO and Google Scholar to identify cross-sectional school-based studies published during 1990-2020. Studies with pre-identified mental illness were excluded. Heterogeneity between studies were examined and estimates were pooled using a random-effects model. Subgroup and sensitivity analysis were performed. Publication bias was evaluated using funnel plot and Egger's test. We included 13 studies in the meta-analysis. The random effect meta-analysis revealed that the pooled prevalence of depression among school going adolescents was 53\% (95\% CI: 41\% - 65\%). By gender, the prevalence was 50\% (95\% CI: 38\%-62\%) in males and 57\% (95\% CI: 46\% - 69\%) in females. The subgroup analysis revealed that the pooled prevalence increased with the education levels (High school: 42\%; High school and pre-university: 55\%; and Pre-university: 67\%). In this review we found that more than half of the school going adolescents in India suffered from depression that ranged from mild to severe. These results draw attention to re-look at the mental health policy and newer public health approaches to address depression. Further, strengthening schoolbased mental health services, along with the community and center-based care is crucial to prevent and effective management of depression among adolescents.
\end{abstract}

Keywords: Adolescent, Cross sectional, Depression, India, Meta-analysis, Systematic review

\section{INTRODUCTION}

Mental health disorders have emerged as major health problem; accounting for $11.1 \%$ of total disease burden in Low and Middle-Income countries (LMICs). ${ }^{1}$ It is the second leading cause of disease burden (in terms of Years lived with disability). ${ }^{2}$ Among all the mental health disorders, depression affects 300 million of population world-wide and has become the pre-eminent cause of disease burden among adolescents (10-19 years of age). ${ }^{3-5}$ The world-wide prevalence of depression in adolescence ranges from $15-20 \% .^{6}$ Almost $50 \%$ of mental health conditions begin at the age of 14 years. ${ }^{7}$ In India one in four adolescents aged 13-15 years have experienced depression with overall prevalence ranging from 15 to $40 \% .^{8,9}$ Depression in adolescents is often an under detected condition in LMICs and adolescents are more likely to remain untreated posing a major challenge to 
health systems. ${ }^{1,8}$ Research suggest that more than $70 \%$ of the global children with depression do not receive an appropriate diagnosis and treatment, which may be due to the inadequacy of an ideal screening test or assessment tools for depression assessments or due to the reluctance in seeking professional help. ${ }^{10}$ This is also related to inadequate capacity of health systems. ${ }^{1}$

Depression in adolescent is mostly associated with impaired school performance, lack of supportive school environment, school dropout, unhealthy relationships, toxic family environment, substance abuse, sexual abuse, internet addiction, risky sexual behaviors and economic difficulties. ${ }^{11,12}$ Genetic factors, biological changes associated with puberty, cognitive and socio-cultural factors are few predisposing factors for the occurrence of the depression. ${ }^{13}$ Depression is usually characterized by lack of interest or pleasure, mood changes, psychomotor agitation or retardation, fatigue, loss of energy, inability to concentrate, loss of appetite/increased appetite, weight loss, worthlessness or guilt and recurrent thoughts of selfharm/suicide. ${ }^{10}$ Mostly the transition from childhood to adulthood results in emotional instability and individuals often face difficulty in establishing their self-identity and self-esteem, which further make them vulnerable to depressive disorders at this age. ${ }^{14}$

The Indian National Mental Health Program and National Mental Health Policy aims to reduce morbidity of mental illness including depression by improving access to prevention and treatment through strengthening care at primary and secondary healthcare levels.

The District Mental Health Program has incorporated school mental health services by providing life skills education, counseling services through trained teachers for school and college going children. ${ }^{15}$ However, the focus has remained mainly on learning and behavior disorders of children without knowing the estimation of different types of mental illness among schoolgoing adolescents. ${ }^{16}$

Most of the scientific studies which report the prevalence of depression in India have varied in their approach, sample size, settings, target population and tools. So, in the absence of targeted national level surveys, there is a greater need to synthesize good quality data from crosssectional studies to know the disease burden. With this purpose we have undertaken a systematic review to estimate the pooled prevalence of depression among schoolgoing adolescents in India.

\section{METHODS}

\section{Protocol and registration}

The Systematic review protocol was registered in the International Prospective Register of Systematic Reviews (PROSPERO) (Registration number: CRD42020193980). We followed the Preferred Reporting Items for
Systematic Reviews and Meta-Analyses (PRISMA) guidelines through-out our review.

\section{Eligibility criteria}

In this review we included cross-sectional studies published from 1990 to 2020 in India that report prevalence of depression among adolescents by using Beck's Depression Inventory (BDI 1 or BDI 2). ${ }^{17}$ Furthermore, school-based studies were included because in recent time schools have been attracted as a formal infrastructure to promote mental health services along with the health related activities. ${ }^{18}$ Studies without preidentified mental illness were included and those with known mental illness were excluded.

The BDI tool was preferred over other screening tools because it is widely used in school-based studies and it was found to be a better screening tool. ${ }^{19}$ BDI has a 21item, self-report rating scale that measures characteristic, attitudes and symptoms of depression. The various forms of BDI has been developed which is comprised of several computerized forms, a card form, the 13-item short form and the most recent one is BDI 2. The BDI takes almost ten minutes to complete and participants require a fifthsixth grade reading level to understand the questions effectively.

\section{Information sources}

A systematic review and meta-analysis were conducted using published studies on the prevalence of depression among schoolgoing adolescents in India. We searched for published literature using electronic databases such as PubMed, Ovid MEDLINE, Ovid EMBASE, CINAHL, Cochrane Library, PsycINFO and Google Scholar. The Google Scholar search was limited to the first 70 relevant articles. An additional manual search was also conducted for relevant articles. Search was conducted on 24th June, 2020 and updated on 29th June 2020. We also looked for literature on the national health mission website for national level surveys.

\section{Search}

We identified keywords from the review question and identified appropriate synonyms and built a search strategy. During comprehensive literature search the following search terms were included (Adolescent OR School-going OR School going* OR Children OR PreUniversity) AND (Depression) AND (Prevalence OR Cross-sectional study OR Cross sectional OR Schoolbased) AND (India). Additionally, we performed a manual search of citations from the relevant published articles. The search was restricted to English language.

\section{Data collection process}

Search results from different databases were downloaded in RIS format and uploaded into Rayyan QCRI and 
duplicates were removed. It was shared with the research team in a blind mode. Two independent researchers screened the titles and abstracts and included the studies that met the inclusion criteria. About $10 \%$ of articles were reviewed by a 3rd reviewer. Following which a call was held with the team members and conflicts were resolved. Further, we reviewed the full text of relevant articles against eligibility criteria and included a finite number of articles for data extraction.

Data extraction form was developed and piloted before we agreed upon the variables. Data extraction form included the following information- study and publication details, study location, type of school, grades, participant characteristics, research design, socio-economic variables, response rate, depression assessment tool and cut-off scores, sample size and prevalence of depression. We also contacted corresponding authors for unavailability of data.

\section{Risk of bias in individual studies}

A quality assessment checklist for prevalence studies, adapted from Hoy et al was used to perform the critical appraisal of the included studies. ${ }^{20}$ It consists of nine questions that assess the external and internal validity of the study and a 10th item which contains the overall risk of study bias. Each item in the checklist was scored either as " 0 " or " 1 " according to "low risk of bias" and "high risk of bias". The total score ranged from ' 0 to 9 ' with the overall score categorized as low risk (0-3), moderate risk (4-6) and high risk (7-9) respectively. The methodological quality and eligibility of the identified articles were also assessed by two reviewers and disagreements among reviewers were fixed accordingly followed by a discussion.

\section{Data analysis and synthesis}

The extracted data was analyzed in STATA 15. The pooled prevalence was estimated from the proportion of prevalence of depression from individual studies. Due to heterogeneity between studies, meta-analysis was performed with a random effect model using restricted maximum likelihood (REML) estimates. Heterogeneity was assessed by the inconsistency index I and the Q test. ${ }^{2}$ Statistical heterogeneity was declared using the $\mathrm{Q}$ test $\mathrm{P}$ value $\leq 0.05$. Forest plots were used to visualize the prevalence in each study and the combined estimated prevalence with their $95 \%$ confidence intervals (95\% CI).

\section{Subgroup and sensitivity analysis}

Subgroup analysis based on the education level categories and sensitivity analyses based on the sample size were performed to address heterogeneity. Publication bias was assessed graphically using funnel plots and tested using Egger's method. A $p$ value $\leq 0.05$ was considered for statistical significance. All statistical analyses were performed with STATA 15.

\section{RESULTS}

\section{Study selection}

A total of 510 studies were identified through database search and six additional articles were identified through other sources. After removing 151 duplicates, 365 articles were screened for title and abstract. Screening of title and abstract resulted in exclusion of 312 irrelevant articles. Total 53 articles were assessed for full text screening, out of which 40 articles were excluded with reasons (Figure 1) We finalized a total 13 studies that were eligible for full text data extraction. ${ }^{9,10,14,21-30}$

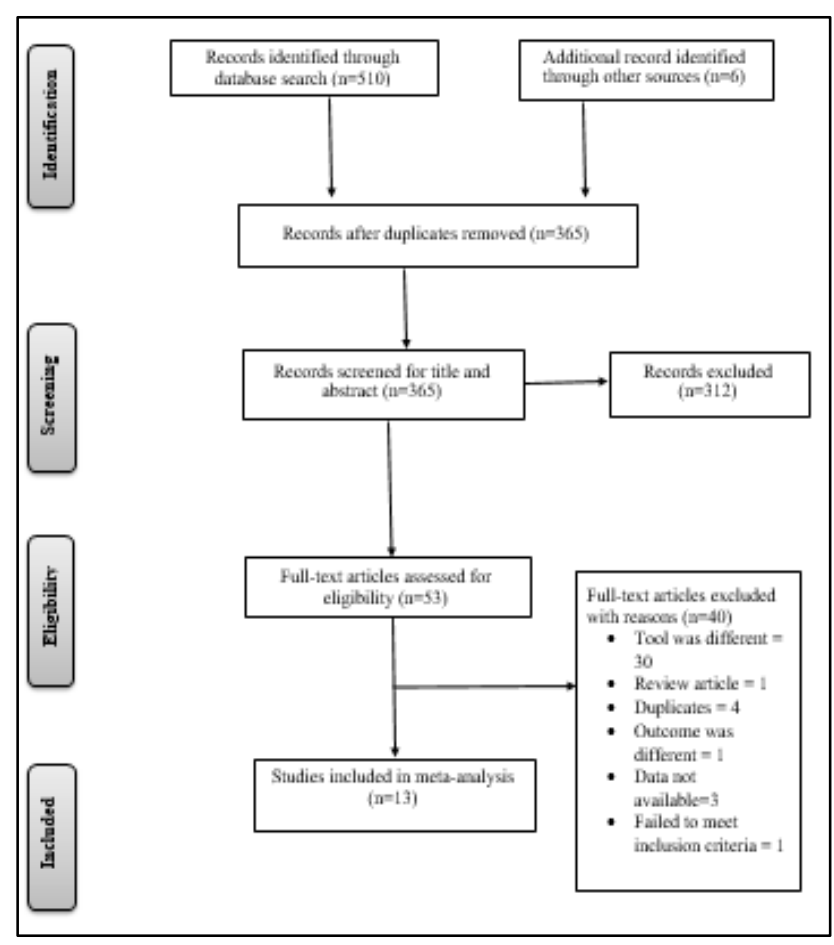

Figure 1: PRISMA flow chart.

\section{Study characteristics}

Characteristics of included studies were summarized in Table 1. A total of 13 cross-sectional studies were included for the Meta-analysis. Studies took place in different states of India. Four studies were conducted in Karnataka and one study each in Bihar, Chandigarh, Haryana, Kerala, Madhya Pradesh, Maharashtra, Tamil Nadu, West Bengal and South India (state not specified)..$^{9,10,14,21-30}$ In these studies, the participant's age group ranged from 13 to 19 years. Total sample size was 8898, among which 4710 were males and 3430 were girls. Out of 13 studies, nine studies reported the type of school. Four studies took place in public schools (run by the government), two in private and three took place in both government and private schools. Studies had used either BDI 1 or BDI 2 to report depression. Adolescents were studying in different grades ranging from 7 th standard to pre-university. 
To compare the prevalence across the studies we considered mild, moderate, severe and extremely severe depression categories reported in individual studies.

\section{Prevalence of depression}

Thirteen studies were included in the meta-analysis, with a total population of 8898 subjects. Random effects models were used to summarize the prevalence as there was a high level of significant heterogeneity $\left(\mathrm{I}^{2}=99 \%\right.$, $\mathrm{p}<0.001)$. The random effect Meta-analysis revealed that the pooled prevalence of depression among Indian adolescents was 53\% (95\% CI: 41\%-65\%) (Figure 2) Prevalence was higher in females 57\% (95\% CI: 46\%$69 \%$ ) than male adolescents $50 \%$ (95\% CI: 38\%-62\%) (Figure 3) (Figure 4).

Table 1: Characteristics of included studies $(n=13)$.

\begin{tabular}{|c|c|c|c|c|c|c|c|c|}
\hline $\begin{array}{l}\text { Author } \\
\text { Name }\end{array}$ & $\begin{array}{l}\text { Year of } \\
\text { publication }\end{array}$ & State & $\begin{array}{l}\text { Age in years } \\
\text { Range (Mean) }\end{array}$ & $\begin{array}{l}\text { Sample } \\
\text { size }\end{array}$ & $\begin{array}{l}\text { Male } \\
(\mathbf{N})\end{array}$ & $\begin{array}{l}\text { Female } \\
(\mathbf{N})\end{array}$ & $\begin{array}{l}\text { Type of } \\
\text { school }\end{array}$ & Grade \\
\hline Jha et al & 2017 & Bihar & $14-18$ & 1485 & 893 & 519 & N/A & 9 to 12 \\
\hline $\begin{array}{l}\text { Sharma et } \\
\text { al }\end{array}$ & 2014 & Chandigarh & N/A & 300 & 150 & 150 & Govt & 11 \\
\hline $\begin{array}{l}\text { Malik et } \\
\text { al }\end{array}$ & 2015 & Haryana & $\begin{array}{l}13-17 \\
\text { Mean-15.13 }\end{array}$ & 374 & 254 & 120 & Govt & 9 to 10 \\
\hline $\begin{array}{l}\text { Jayashree } \\
\text { et al }\end{array}$ & 2018 & Karnataka & $15-18$ & 201 & 128 & 73 & N/A & $\begin{array}{l}\text { High school } \\
\text { and Pre- } \\
\text { University }\end{array}$ \\
\hline \multirow[b]{2}{*}{$\begin{array}{l}\text { Joseph et } \\
\text { al }\end{array}$} & \multirow[b]{2}{*}{2011} & \multirow[b]{2}{*}{ Karnataka } & $16-19$ & \multirow[b]{2}{*}{308} & \multirow[b]{2}{*}{205} & \multirow[b]{2}{*}{103} & \multirow[b]{2}{*}{ Both } & \multirow{2}{*}{$\begin{array}{l}\text { Pre- } \\
\text { University } \\
\text { students }\end{array}$} \\
\hline & & & Mean-17.27 & & & & & \\
\hline $\begin{array}{l}\text { Nagendra } \\
\text { et al }\end{array}$ & 2012 & Karnataka & $15-19$ & 3126 & 1841 & 1285 & Both & $\begin{array}{l}\text { High schools, } \\
\text { pre-university } \\
\text { colleges, } \\
\text { Industrial } \\
\text { Training } \\
\text { Institute (ITI) }\end{array}$ \\
\hline Sinha et al & 2020 & Karnataka & 15-18 & 254 & 110 & 144 & Govt & 9 to 10 \\
\hline Nair et al & 2004 & Kerala & 13-19 & 898 & 430 & 468 & N/A & 9,11 and 12 \\
\hline $\begin{array}{l}\text { Rama et } \\
\text { al }\end{array}$ & 2016 & $\begin{array}{l}\text { Madhya } \\
\text { Pradesh }\end{array}$ & $14-16$ & 136 & 80 & 56 & Private & 9 to 10 \\
\hline $\begin{array}{l}\text { Bansal et } \\
\text { al }\end{array}$ & 2009 & Maharashtra & N/A & 125 & N/A & N/A & Govt & 9 \\
\hline $\begin{array}{l}\text { Jayanthi } \\
\text { et al }\end{array}$ & 2015 & South India & $14-17$ & 560 & N/A & N/A & Both & 9 to 12 \\
\hline $\begin{array}{l}\text { Mohanraj } \\
\text { et al }\end{array}$ & 2010 & Tamil Nadu & $\begin{array}{l}\text { 14-18 } \\
\text { Mean-15.6 }\end{array}$ & 964 & 509 & 455 & Private & 10,11 and 12 \\
\hline Basu et al & 2017 & $\begin{array}{l}\text { West } \\
\text { Bengal }\end{array}$ & $13-17$ & 167 & 110 & 57 & N/A & 7 to 9 \\
\hline
\end{tabular}

\section{Subgroup analysis}

Subgroup analysis based on the education level categories and sensitivity analyses based on the sample size were performed to address heterogeneity. The subgroup analysis revealed that the pooled prevalence increased with education levels (High school: 42\%; High school and pre-university: 55\%; and Pre-university: 67\%) (Figure 5).

\section{Sensitivity analysis}

Sensitivity analysis performed by excluding the studies with sample size less than 200 which did not affect the overall estimate..$^{9,27,30}$ The pooled prevalence found to be $57 \%$ (95\% CI: 44\%-69\%) (Figure 6).

\section{Risk of bias between studies}

All the studies were found to be low risk of bias when assessed by Hoy et al checklist. ${ }^{20}$ The most of the studies failed to meet question 2 and question 4 of the checklist. In most of the studies sampling frame was not a close representation of the target population and no clear information was available to evaluate response rate. All the studies had collected data directly from the participants (Table 2). 
$\mathrm{Y}=$ Yes (Low risk), N= No (High risk)

- Was the study's target population a close representation of the national population in relation to relevant variables, e.g. age, sex, occupation?

- Was the sampling frame a true or close representation of the target population?

- Was some form of random selection used to select the sample, OR, was a census undertaken?

- Was the likelihood of non-response bias minimal?

- Were data collected directly from the subjects (as opposed to a proxy)?

- Was an acceptable case definition used in the study?

- Was the study instrument that measured the parameter of interest (e.g. prevalence of low back pain) shown to have reliability and validity (if necessary)?

- Was the same mode of data collection used for all subjects?

- Were the numerator(s) and denominator(s) for the parameter of interest appropriate?

- Overall scores

Risk of bias levels based on overall scores i.e. 0-3=Low risk, 4-6=Moderate, 7-9=High risk

\section{Publication bias}

Publication bias was evaluated using funnel plot and Egger's test. Test revealed that there was no significant publication bias $(\mathrm{P}=0.50)$ (Figure 7$)$.

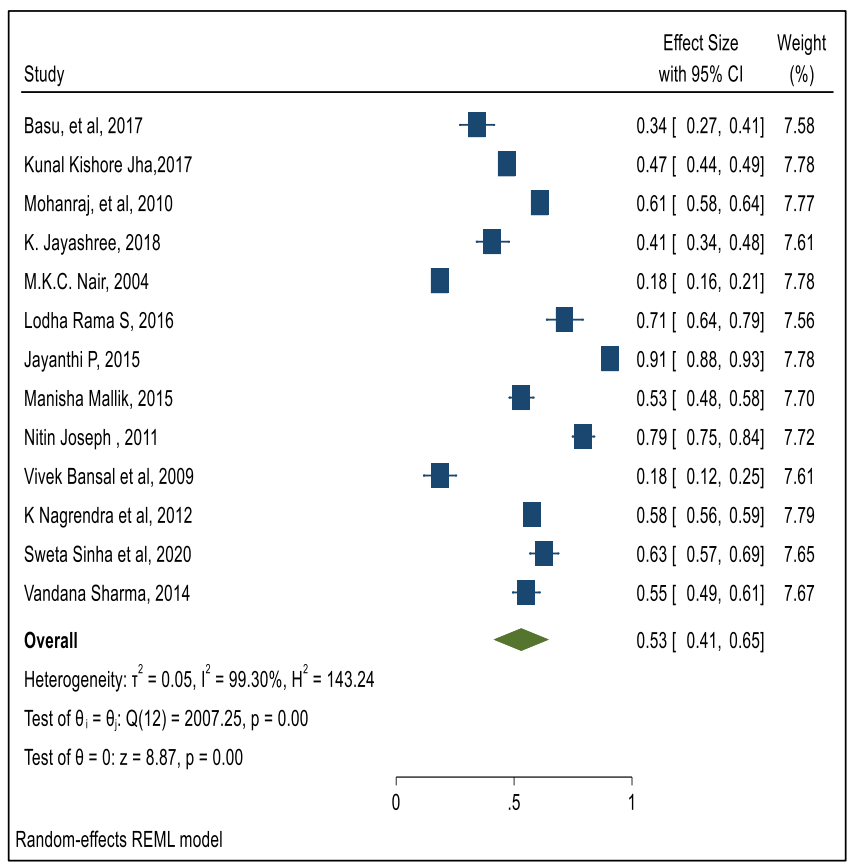

Figure 2: Meta-analysis and forest plot of included studies.

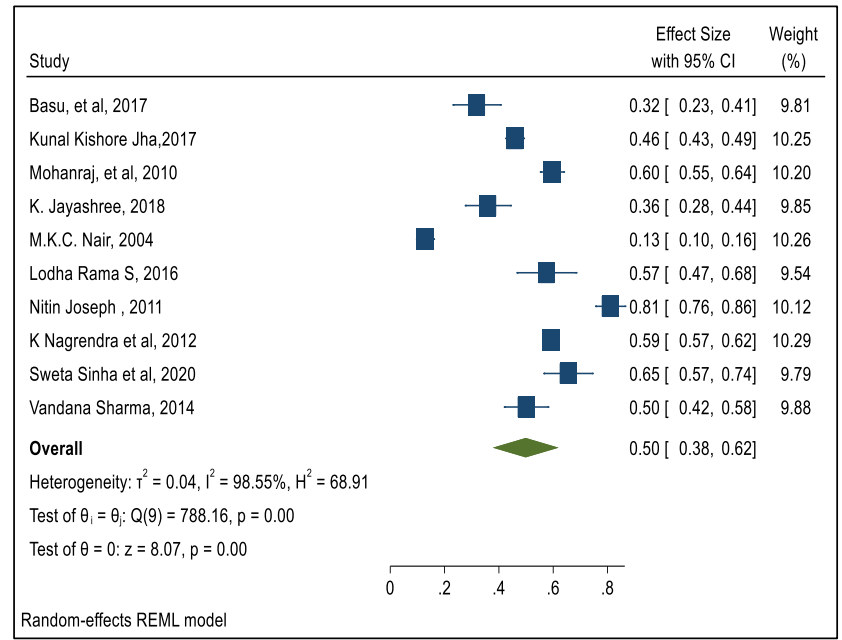

Figure 3: Meta analysis and forest plot of included studies.

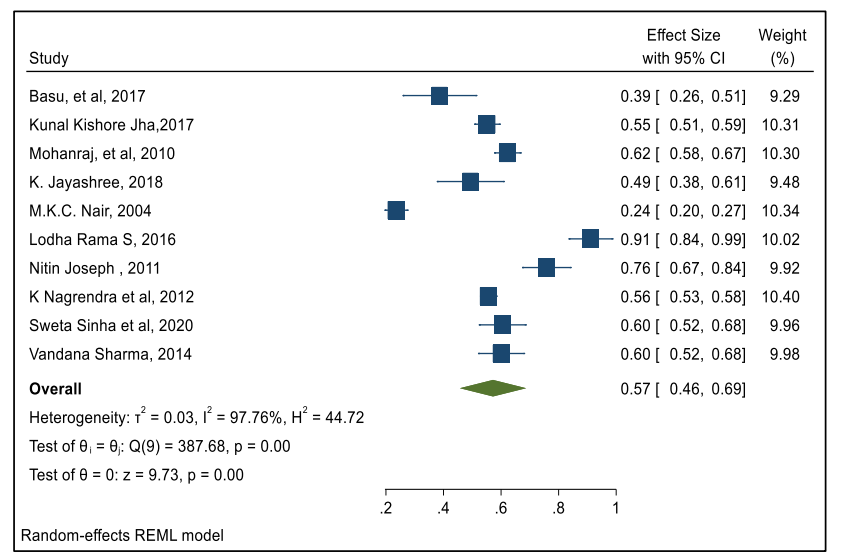

Figure 4: Meta analysis and forest plot (Female).

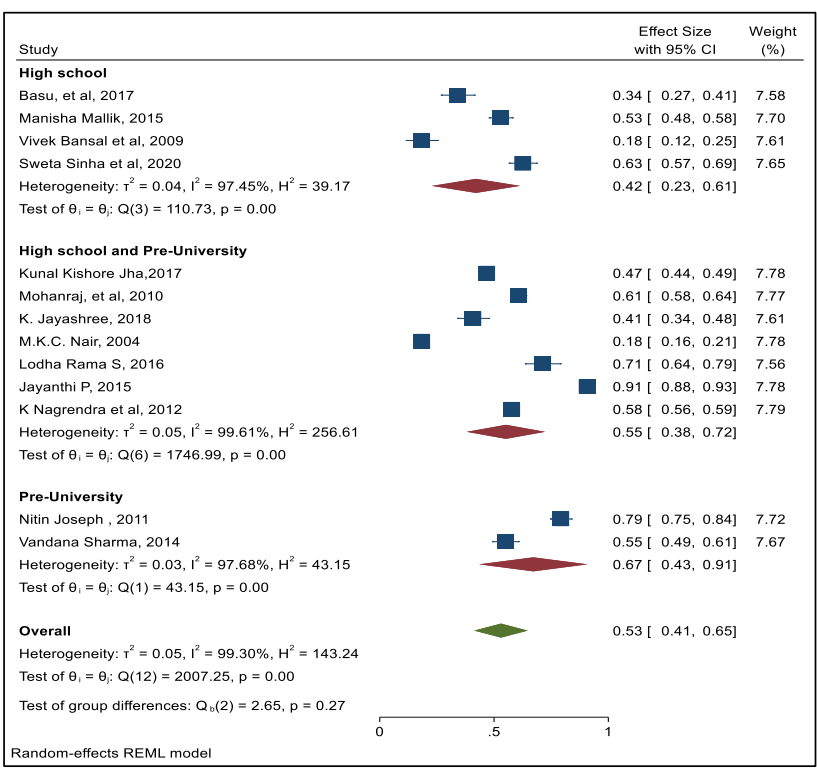

Figure 5: Subgroup analysis based on education level and forest plot. 


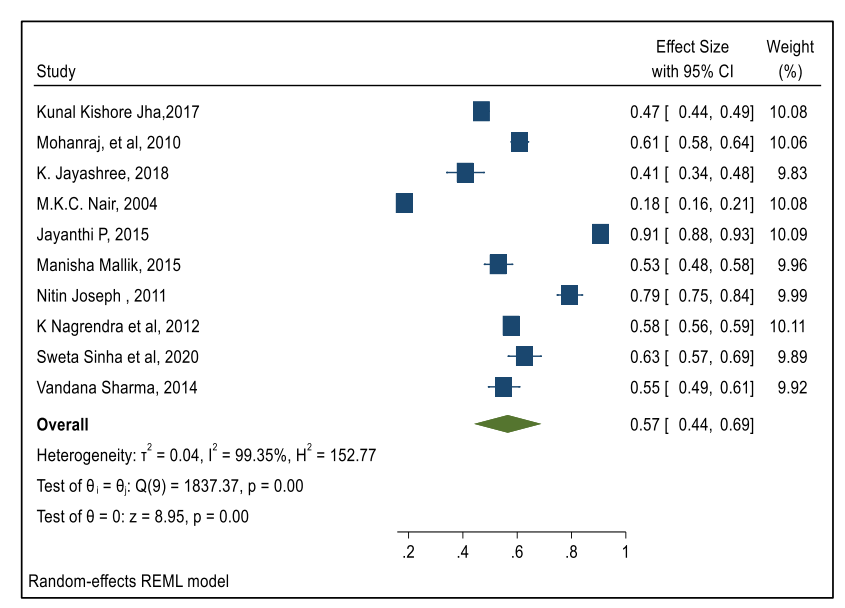

Figure 6: Sensitivity analysis and forest plot.

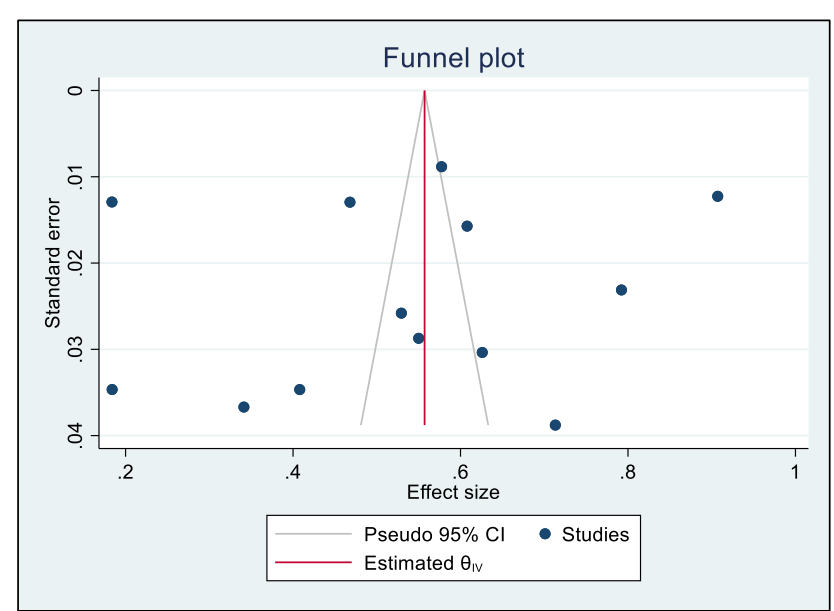

Figure 7: Publication bias.

Table 2: Risk of bias assessment.

\begin{tabular}{|c|c|c|c|c|c|c|c|c|c|c|c|}
\hline \multirow{2}{*}{ Studies } & \multicolumn{10}{|c|}{ Criteria } & \multirow{2}{*}{$\begin{array}{l}\text { Risk bias } \\
\text { levels }\end{array}$} \\
\hline & $1 *$ & $2 *$ & $3 *$ & $4 *$ & $5 *$ & $6^{*}$ & $7 *$ & $8 *$ & $9 *$ & $10 *$ & \\
\hline Basu et al, 2017 & $\mathrm{Y}$ & $\mathrm{N}$ & $\mathrm{N}$ & $\mathrm{Y}$ & $\mathrm{Y}$ & $\mathrm{Y}$ & $\mathrm{Y}$ & $\mathrm{Y}$ & $\mathrm{Y}$ & 2 & Low risk \\
\hline Kunal Kishore Jha, 2017 & $\mathrm{Y}$ & $\mathrm{N}$ & $\mathrm{Y}$ & $\mathrm{Y}$ & $\mathrm{Y}$ & $\mathrm{Y}$ & $\mathrm{Y}$ & $\mathrm{Y}$ & $\mathrm{Y}$ & 1 & Low risk \\
\hline Mohanraj et al, 2010 & $\mathrm{Y}$ & $\mathrm{N}$ & $\mathrm{Y}$ & $\mathrm{Y}$ & $\mathrm{Y}$ & $\mathrm{Y}$ & $\mathrm{Y}$ & $\mathrm{Y}$ & Y & 1 & Low risk \\
\hline K. Jayashree, 2018 & $\mathrm{Y}$ & $\mathrm{N}$ & $\mathrm{N}$ & $\mathrm{Y}$ & $\mathrm{Y}$ & $\mathrm{N}$ & $\mathrm{Y}$ & $\mathrm{Y}$ & $\mathrm{Y}$ & 3 & Low risk \\
\hline M.K.C. Nair, 2004 & $\mathrm{Y}$ & $\mathrm{Y}$ & $\mathrm{N}$ & $\mathrm{N}$ & $\mathrm{Y}$ & $\mathrm{Y}$ & $\mathrm{Y}$ & $\mathrm{Y}$ & $\mathrm{Y}$ & 2 & Low risk \\
\hline Lodha Rama S, 2016 & $\mathrm{Y}$ & $\mathrm{N}$ & $\mathrm{Y}$ & $\mathrm{N}$ & $\mathrm{Y}$ & $\mathrm{Y}$ & $\mathrm{Y}$ & $\mathrm{Y}$ & $\mathrm{Y}$ & 2 & Low risk \\
\hline Jayanthi P, 2015 & $\mathrm{Y}$ & $\mathrm{Y}$ & $\mathrm{N}$ & $\mathrm{N}$ & $\mathrm{Y}$ & $\mathrm{N}$ & $\mathrm{Y}$ & $\mathrm{Y}$ & $\mathrm{Y}$ & 3 & Low risk \\
\hline Manisha Mallik, 2015 & $\mathrm{Y}$ & $\mathrm{N}$ & $\mathrm{N}$ & $\mathrm{N}$ & $\mathrm{Y}$ & $\mathrm{Y}$ & $\mathrm{Y}$ & $\mathrm{Y}$ & $\mathrm{Y}$ & 3 & Low risk \\
\hline Nitin Joseph, 2011 & $\mathrm{Y}$ & $\mathrm{Y}$ & $\mathrm{Y}$ & $\mathrm{Y}$ & $\mathrm{Y}$ & $\mathrm{Y}$ & $\mathrm{Y}$ & $\mathrm{Y}$ & $\mathrm{Y}$ & 0 & Low risk \\
\hline Vivek Bansal et al, 2009 & $\mathrm{~N}$ & $\mathrm{~N}$ & $\mathrm{Y}$ & $\mathrm{N}$ & $\mathrm{Y}$ & $\mathrm{Y}$ & $\mathrm{Y}$ & $\mathrm{Y}$ & $\mathrm{Y}$ & 3 & Low risk \\
\hline K Nagendra et al, 2012 & $\mathrm{Y}$ & $\mathrm{Y}$ & $\mathrm{Y}$ & $\mathrm{Y}$ & $\mathrm{Y}$ & $\mathrm{Y}$ & $\mathrm{Y}$ & $\mathrm{Y}$ & $\mathrm{Y}$ & 0 & Low risk \\
\hline Sweta Sinha et al, 2020 & $\mathrm{Y}$ & $\mathrm{N}$ & $\mathrm{Y}$ & $\mathrm{Y}$ & $\mathrm{Y}$ & $\mathrm{Y}$ & $\mathrm{Y}$ & $\mathrm{Y}$ & $\mathrm{Y}$ & 1 & Low risk \\
\hline Vandana Sharma, 2014 & $\mathrm{~N}$ & $\mathrm{~N}$ & $\mathrm{Y}$ & $\mathrm{Y}$ & $\mathrm{Y}$ & $\mathrm{N}$ & $\mathrm{Y}$ & $\mathrm{Y}$ & $\mathrm{Y}$ & 3 & Low risk \\
\hline
\end{tabular}

\section{DISCUSSION}

The systematic review and meta-analysis were conducted to estimate the pooled prevalence among schoolgoing adolescents in India. In this review, the estimated pooled prevalence of depression was found to be $53 \%$ (95\% CI: 41\%-65\%). The pooled prevalence reported in our review was within the range of point prevalence reported in a similar review performed on schoolgoing children, ranging from $3 \%$ to $68 \%$; most of the individual studies reported prevalence of $>40 \% .{ }^{31}$ A cross-sectional survey of undergraduate medical students in Gujrat, when assessed using Patient Health Questionnaire (PHQ-9) reported overall prevalence of $65 \%$ which is comparable with the findings of our review. ${ }^{32}$

There were limited reviews conducted on school-based setting in India however, in South Asian region, China has conducted several reviews on school-based studies. The pooled prevalence found in our review was higher than prevalence reported in Chinese reviews. The average pooled prevalence among college going children was
$30.39 \%$, on secondary school students it was reported to be $24.3 \%$ (95\% CI: $21.3 \%-27.6 \%$ ) and in another review among children and adolescent of less than 18 years of age depression was found to be $19.85 \%$ (95\% CI: $14.75 \%-24.96 \%$ ), one more review on primary school students with lesser prevalence of $17.2 \% .^{33-36}$

Results of pooled prevalence gives new insights to relook at the prevention strategies through strengthening of school-based mental health services along with the community and center-based care. Our review showed an increased trend of depression as adolescent progress towards higher educational level. Similar trend was also established in a recent meta-analysis conducted in China. An increase in prevalence of $24.5 \%$ (95\% CI: $17.8 \%-$ $32.8 \%$ ) to $40.1 \%$ (95\% CI: $29.4 \%-51.9 \%$ ) from Year 1 in Junior secondary school to year 3 in senior secondary school was reported. ${ }^{34}$ These findings emphasize the need to consider age-specific developmental needs and prevention strategies by early (10-13), middle (14-17) and late adolescent period (18-19 years). Gender has appeared as a foremost factor associated with depression. 
Prevalence of depression was found higher among females than males which is consistent with the Iranian systematic review where it showed that mean prevalence of depression higher among girls than boys. ${ }^{37}$ The high prevalence of depression among females might be associated with the changes during puberty. ${ }^{38}$

We found minimal methodological issues in included studies. All the studies included were having low risk of bias when assessed using Hoy et al checklist which may slightly differ compared to other quality assessment checklists for cross-sectional studies. ${ }^{20,38}$ Even though BDI is a widely used and validated tool, the cut-off score and categories differed which was challenging to compare between studies. In our review, prevalence is comprehensive of depression status (from mild to extremely severe), could be an overestimation of the depression.

We followed a sound scientific methodology through-out our review. Our review would contribute to the evidence base for country specific adolescent mental health policies by estimating the burden of depression among adolescents. Given the various tools for the assessment of depression our review focused on the studies that used the BDI tool to measure depression which is a validated and reliable tool; hence more likely to provide a precise measurement of depression.

In the Meta-analysis a significant heterogeneity among studies was reported and we tried to address heterogeneity with a sensitivity and sub-group analysis that needs to be considered when interpreting the results of this review. The extraneous variables such as home environment, family income, parent-child relationship and supporting mechanisms were not assessed since most of the individual studies did not report these variables. Most of the studies were conducted in South India, which lacked the real representation of studies from North-East, North-West regions of India.

\section{CONCLUSION}

The study revealed that the schoolgoing adolescents across India frequently experienced depressive symptoms and the levels of depression at this age group ranged from mild to severe. This calls for an urgent need to impart adequate awareness in parents, teachers and peer groups, as well as to sensitize them regarding the intensity of the disease, so that early identification and treatment can be accomplished. Despite the efforts by the government in public health facilities and community level, lack of human resources, infrastructure and stigma associated with the disease has been challenging to provide quality mental health. One of the cost-effective ways to address mental health in adolescents is through strengthening school-based programs with an integrated approach by the health and education departments. School teachers could be the potential candidates to empower with the skills of identifying early symptoms of mental illness, that would later help to draw the attention of the health department.

\section{ACKNOWLEDGEMENTS}

Authors would like to acknowledge Biostatistical Constancy Centre (BCC) for providing statistical assistance during this review.

Funding: No funding sources

Conflict of interest: None declared

Ethical approval: Not required

\section{REFERENCES}

1. Patel V. Mental health in low- and middle-income countries. British Medical Bulletin. 2007;(4):81-96.

2. WHO. The burden of mental disorders across the states of India: the global burden of disease study 1990-2017. Lancet Psychiatry. 2019;1-14.

3. Herrman H, Kieling C, McGorry P, Horton R, Sargent J, Patel V. Reducing the global burden of depression: a Lancet-World Psychiatric Association Commission. The Lancet. 2019;393(10189):42-3.

4. Ferrari AJ, Charlson FJ, Norman RE, Patten SB, Freedman G, Murray CJL, et al. Burden of depressive disorders by country, sex, age, and year: findings from the global burden of disease study 2010. Hay PJ, Editor. PLoS Med. 2013;10(11):e1001547.

5. WHO. Caring for children and adolescents with mental disorders: setting WHO directions. Available at http://www.myilibrary.com?id=9727. Accessed on 17 September 2020.

6. Asarnow JR, Jaycox LH, Duan N, LaBorde AP, Rea MM, Murray P, et al. Effectiveness of a quality improvement intervention for adolescent depression in primary care clinics: A randomized controlled Trial. JAMA. 2005;293(3):311.

7. WHO. Adolescent Mental Health. Available at https://www.who.int/news-room/fact-sheets/detail/ adolescent-mental-health. Accessed on 17 September 2020.

8. World Health Organization, Regional Office for South-East Asia. mental health status of adolescents in South-East Asia: evidence for action. 2017.

9. Bansal V, Goyal S, Srivastava K. Study of prevalence of depression in adolescent students of a public school. Ind Psychiatry J. 2009;18(1):43.

10. Jha K, Singh S, Nirala S, Kumar C, Kumar P, Aggrawal N. Prevalence of depression among school-going adolescents in an Urban area of Bihar, India. Indian J Psychol Med. 2017;39(3):287.

11. Dhanasekara PR, Sreeranjini T, Aiman A, John S, Prabhu S, Shrinivasa BU, et al. A Study on the prevalence of depression among young adults in South India. Indian J Ment Heal. 2016;4(1):24.

12. Basker M, Moses PD, Russell S, Russell P. The psychometric properties of beck depression inventory for adolescent depression in a primary- 
care paediatric setting in India. Child Adolesc Psychiatry Ment Health. 2007;1(1):8.

13. Breslau N, Peterson EL, Schultz LR, Chilcoat HD, Andreski P. Major depression and stages of smoking: a longitudinal investigation. Arch Gen Psychiatry. 1998;55(2):161.

14. Joseph DN. prevalence of depression among preuniversity college students in an urban area of south India. Int J Curr Res. 2011;3:4.

15. Khurana S, Sharma S. National mental health program of India: a review of the history and the current scenario. Int J Community Med Public Health. 2016;2:697-704.

16. Mangal A, Thakur A, Nimavat K, Dabar D, Yadav S. Screening for common mental health problems and their determinants among school-going adolescent girls in Gujarat, India. J Fam Med Prim Care. 2020;9(1):264.

17. Beck's Depression Inventory. Available at https://www.ismanet.org/doctoryourspirit/pdfs/ Beck-Depression-Inventory-BDI.pdf. Accessed on 17 September 2020.

18. Mina F, Kimberly H, Sharon S, Tamsin F. Mental health interventions in schools. Lancet Psych. 2009;1(5):377-87.

19. Russell PS, Basker M, Russell S, Moses PD, Nair MKC, Minju KA. Comparison of a self-rated and a clinician-rated measure for identifying depression among adolescents in a primary-care setting. Indian J Pediatr. 2012;79(S1):45-51.

20. Hoy D, Brooks P, Woolf A, Blyth F, March L, Bain $\mathrm{C}$, et al. Assessing risk of bias in prevalence studies: modification of an existing tool and evidence of interrater agreement. J Clin Epidemiol. 2012;65(9):934-9.

21. Sharma V. Prevalence of depression among adolescents: a comparative analysis. Paripex. Indian J Res. 2012;3(6):53-5.

22. Malik M, Khanna P, Rohilla R, Mehta B, Goyal A. Prevalence of depression among school going adolescents in an urban area of Haryana, India. Int J Community Med Public Health. 2015;624-6.

23. Jayashree K, Mithra P, Nair M, Unnikrishnan B, Pai K. Depression and anxiety disorders among schoolgoing adolescents in an urban area of South India. Indian J Community Med. 2018;43(5):28.

24. K N, D S, C G, Nk K. prevalence and association of depression and suicidal tendency among adolescent students. Int J Biomed Adv Res. 2012;3(9):714-9.

25. Sinha S, Patil MS, Viveki RG, Halki S. Prevalence of depression among school going adolescents in an urban area of Karnataka, India: a cross sectional study. Int $\mathbf{J}$ Community Med Public Health. 2020;7(5):1790.

26. Nair MKC, Paul MK, John R. Prevalence of depression among adolescents. Indian $\mathrm{J}$ Pediatr. 2004;71(6):523-4.
27. Rama SL, Patel S, Maata S, Negi P, Sahu N, DKP, et al. Prevalence of depression amongst higher secondary school adolescents in Bhopal Madhya Pradesh. Ntl J Community Med. 2016;7(11):856-8.

28. P J, M T. Prevalence of Depression among School Going Adolescents in South India. IJPCR. 2015;7(1):61-3.

29. Mohanraj R, Subbaiah K. Prevalence of depressive symptoms among rural adolescents in South India. J Indian Assoc Child Adolesc Ment Health. 2010;6(2):33-43.

30. Basu G, Biswas S. Mental health and depression among school going adolescents: excerpts from a school based study of Nadia district, West Bengal. Asian J Med Sci. 2017;8(5):64-9.

31. Grover S, Raju VV, Sharma A, Shah R. Depression in children and adolescents: a review of indian studies. Indian Psych Soc. 2019;41(3):216-27.

32. Vankar J, Prabhakaran A, Sharma H. Depression and stigma in medical students at a private medical college. Indian J Psychol Med. 2014;36(3):246.

33. Jiang CX, Li ZZ, Chen P, Chen LZ. Prevalence of depression among college-goers in Mainland China: a methodical evaluation and meta-analysis. Medicine (Baltimore). 2015;94(50):e2071.

34. Tang X, Tang S, Ren Z, Wong DFK. Prevalence of depressive symptoms among adolescents in secondary school in mainland China: a systematic review and meta-analysis. J Affect Disord. 2019;245:498-507.

35. Rao WW, Xu DD, Cao XL, Wen SY, Che WI, Ng $\mathrm{CH}$, et al. Prevalence of depressive symptoms in children and adolescents in China: a meta-analysis of observational studies. Psychiatry Res. 2019;272:790-6.

36. Xu DD, Rao WW, Cao XL, Wen SY, An FR, Che WI, et al. Prevalence of depressive symptoms in primary school students in China: A systematic review and meta-analysis. J Affect Disord. 2020;268:20-7.

37. Sajjadi H, Kamal SHM, Rafiey H, Vameghi M, Forouzan AS, Rezaei M. A systematic review of the prevalence and risk factors of depression among iranian adolescents. Global J Health Sci. 2013;5(3):16-27.

38. Conley CS, Rudolph KD. The emerging sex difference in adolescent depression: Interacting contributions of puberty and peer stress. Development and Psychopathology. 2009;21:593620.

Cite this article as: Kamath P, Dsouza SM, Mahapatra S, Jayakumar S. Prevalence of depression among schoolgoing adolescents in India: a systematic review and meta-analysis of cross-sectional studies. Int J Community Med Public Health 2021;8:833-40. 